\title{
Effects of subcutaneous melatonin implants during long daylength on voluntary feed intake, rumen capacity and heart rate of red deer (Cervus elaphus) fed on a forage diet
}

\author{
By B. M. FRANÇOISE DOMINGUE 1 , P. R. WILSON ${ }^{1}$, D. W. DELLOW ${ }^{2 *}$ \\ AND T. N. BARRY $Y^{1 \dagger}$ \\ ${ }^{1}$ Massey University, Palmerston North, New Zealand \\ ' DSIR Grassland, Palmerston North, New Zealand
}

(Received 2 May 1990-Accepted 5 July 1991)

\begin{abstract}
Subcutaneous melatonin implants were administered to castrated hand-reared male red deer (Cervus elaphus) during a $63 \mathrm{~d}$ period in spring, after which effects on voluntary feed intake (VFI), rumen pool size, rumen capacity (i.e. volume) and heart rate were measured on four occasions, evenly spread over a 12-month period, with the deer individually fed indoors on a diet of lucerne (Medicago sativa) chaff. Blood samples for hormone determinations were taken at intervals throughout the study. Day-time plasma melatonin concentration was approximately $5 \mathrm{pg} / \mathrm{ml}$ in control animals, whereas during melatonin administration it increased to $60-150 \mathrm{pg} / \mathrm{ml}$ and declined to $30 \mathrm{pg} / \mathrm{ml}$ by $142 \mathrm{~d}$ after the last implantation. Melatonin administration markedly depressed plasma prolactin concentration during the period of implantation, but thereafter plasma prolactin concentration rose in the treated animals during autumn and winter, whilst it declined in control animals over this period. VFI, rumen pool size and heart rate in control animals attained highest values in summer and lowest values in winter, showing a pronounced seasonal cycle. Melatonin administration depressed all these values in late spring and summer and increased all the values in autumn and winter, relative to control animals, and appeared to move the cycles by approximately 6 months. Melatonin-treated animals showed maximum values for all these measurements during winter. The castrated male deer showed little seasonal change in live weight, which was not affected by melatonin administration. The findings support the view that melatonin probably mediates the effect of daylength on digestive function in red deer. Rumen capacity remained relatively constant throughout the year, but rumen pool size as a proportion of rumen capacity increased with increasing VFI.
\end{abstract}

Voluntary feed intake: Deer: Melatonin: Rumen capacity

The endogenous rhythm of voluntary feed intake (VFI) in red deer (Cervus elaphus) is synchronized by changes in daylength (Simpson et al. 1984; Suttie et al. 1984; Suttie \& Simpson, 1985). High VFI is associated with increasing daylength (spring-summer) and low VFI is associated with decreasing daylength (autumn-winter; Milne et al. 1978; Suttie et al. 1984; Domingue, 1989). Metabolic rate (heat production), heart rate and activity are all greater in summer and lower in winter in the white-tailed deer (Odocoileus virginianus borealis; Silver et al. 1969; Moen, 1978).

Periods of darkness are associated with a rise in plasma concentration of the hormone melatonin (MEL), much above that of day-time levels (Arendt, 1979). As the length of night-time increases from summer to winter, the length of time MEL is secreted is longer (Wurtman \& Anton-Tay, 1969; Plotka et al. 1981; Bittman et al. 1983).

Currently it is known that deer which have been treated with exogenous oral or

* Present address: Animal and Irrigated Pastures Research Institute, Kyabram, Victoria, Australia.

$\dagger$ For reprints. 
subcutaneous (sc) implants of MEL in late spring or early summer show a phase-shift in their reproductive physiology, with an advancement in sexual behaviour and mating in both males and females (Bubenik, 1983; Webster \& Barrell, 1985; Asher et al. 1988; Fisher et al. 1988; Wilson, 1991; Wilson et al. 1991). These results indicate that the exogenous administration of MEL overrides the normal photoperiodic regulation of reproductive physiology in deer. It seems that melatonin acts to block the effects of long days, and functions physiologically to synchronize the seasonal reproductive rhythms to photoperiod; Milne et al. (1990) have provided evidence that the appetite rhythm in deer may also be synchronized to photoperiod by MEL. As VFI, metabolic rate and reproductive rhythms are closely linked in deer (Suttie \& Kay, 1985; Curlewis et al. 1988; Loudon et al. 1989; Barry et al. 1991), it is indeed possible that the effects of daylength on the seasonal VFI cycle are synchronized by MEL.

Objectives of the present experiment were to investigate the effects of constant-release sc implants of MEL on VFI, rumen capacity (i.e. volume), rumen digesta load (pool size) and heart rate (an index of metabolic rate) in castrated male deer, during periods of increasing daylength (spring-summer). This was conducted to see if the seasonal changes in digestive function observed in red deer (Cervus elaphus; Milne et al. 1978), could be altered by exogenous MEL administration, and if the effects of MEL administration persisted over a 12-month period.

High concentrations of plasma prolactin (PRL) have been associated with long daylength, high food intake and rapid weight gain in red deer (Suttie \& Kay, 1985), reindeer (Rangifer tarandus tarandus; Ryg \& Jacobsen, 1982), and in sheep (Forbes et al. 1979). Exogenous MEL administration during long daylength depresses plasma concentration of PRL to base-line levels in deer (Webster \& Barrell, 1985) and in sheep (Kennaway et al. 1983; Lincoln \& Ebling, 1985; Poulton et al. 1986, 1987). The effect of sc implants of MEL on plasma PRL concentration was also measured during the present experiment and related to treatment effects on VFI, rumen capacity and heart rate.

\section{EXPERIMENTA L}

\section{Experimental design}

The first melatonin implants were inserted on 15 September 1988 (day 1), and thereafter every $21 \mathrm{~d}$ for a period of $63 \mathrm{~d}$, with the last implants being administered on 18 November 1988. The MEL administration period was then followed by 4 -week measurement periods (indoor trials) of VFI, rumen capacity, rumen digesta load and heart rate, to determine the immediate, short-term and long-term post-treatment effects of MEL. These were conducted in late November-December 1988 ( $\mathrm{t} 1$; late spring early summer), March 1989 ( $\mathrm{t} 2$; late summer), May 1989 (t3; autumn) and August 1989 (t4; winter).

\section{Animals and management}

Thirteen castrated, hand-reared, male red deer aged 4 years were used, including seven deer fistulated in the rumen and fitted with permanent rubber cannulas (i.d. $83 \mathrm{~mm}$ ), and six nonfistulated deer. The fistulated and non-fistulated deer were balanced for live weight at the start of the experiment (15 September 1988) and allocated to two groups; control (three fistulated and three non-fistulated) and MEL-treated (four fistulated and three nonfistulated). The control group weighed 95.9 (SE 6.82) kg, and the MEL-treated group weighed $95 \cdot 7$ (SE 5.29) kg, at the start of the experiment.

Between the indoor trials the control and treated groups were grazed together on highdigestibility mixed ryegrass (Lolium perenne)-white clover (Trifolium repens) pasture. When housed indoors the animals were kept under natural ambient light regimens. 


\section{MEL treatment}

Two implants, each containing $18 \mathrm{mg}$ MEL (batch 1000695-1; Regulin Ltd, Melbourne, Australia), were inserted subcutaneously at the base of the ear on each occasion using a multi-dose applicator gun with an $8 \mathrm{~mm}$ needle while the animals were restrained in a mechanical deer-crush. All implants were given on the same side of the animal. Implants remained in situ.

\section{Blood sampling}

Heparinized blood samples were collected by jugular venepuncture from control and treated deer, at $10 \mathrm{~d}$ intervals (11.00 hours), from 15 September to 18 November 1988, and again on 5 April 1989 (day 205) and 3 August 1989 (day 322). The latter corresponded to experimental feeding periods 3 and 4 . Samples were kept on ice and later stored at $-20^{\circ}$ for subsequent hormone analysis. Blood sampling was carried out before MEL implantation, with the animals restrained in a deer-crush, and were collected from the vein contralateral to the site of MEL administration.

\section{Live weight recording}

The animals were weighed at $10 \mathrm{~d}$ intervals from 15 September 1988 until 18 November 1988 and thereafter at the beginning and completion of each indoor feeding trial.

\section{Diet}

When kept indoors the animals were fed on lucerne (Medicago sativa) hay containing $896 \mathrm{~g}$ organic matter $(\mathrm{OM}) / \mathrm{kg}$ dry matter $(\mathrm{DM})$ and $29.8 \mathrm{~g} \mathrm{~N} / \mathrm{kg} \mathrm{Dm}$, with an in vitro OM digestibility of 0.71 and an estimated metabolizable energy (ME) value of $9.92 \mathrm{MJ} / \mathrm{kg} \mathrm{DM}$, and were allowed free access to a multi-mineral salt block (Dominion Salt, NZ). The hay was chaffed into $50-80 \mathrm{~mm}$ lengths before feeding. The same batch of lucerne hay was used for all four feeding periods.

\section{Determination of $V F I$}

VFI of lucerne chaff ( $\mathrm{g} / \mathrm{kg}$ live weight ${ }^{0.75}$ per $\mathrm{d}$ ) was measured with the animals kept indoors during the experimental periods $t 1, t 2, t 3$ and $t 4$. The fistulated animals were kept in metabolism crates (Milne et al. 1978; Domingue, 1989) and the non-fistulated animals were kept in individual concrete pens with sawdust provided as bedding.

During each of the experimental periods the animals were allowed an adaptation period of $12 \mathrm{~d}$, with VFI then being measured for $8 \mathrm{~d}$. The animals were fed $a d$ lib., with feed offered being $15 \%$ greater than the previous day's consumption. The non-fistulated animals were fed twice daily, and the fistulated ones were fed continuously at hourly intervals from automatic belt-feeders. Samples of feed offered were collected daily, pooled over the $8 \mathrm{~d}$ measurement period, and stored for chemical analysis. A daily duplicate ovenDM determination was done on the feed refusals of each animal, and also on the feed offered.

\section{Rumen capacity and rumen pool size}

Rumen capacity and rumen pool size (total DM + liquid, DM and liquid pools) were determined $\left(\mathrm{g} / \mathrm{kg} \mathrm{W}^{0.75}\right)$ during each of the experimental periods, using three control and four MEL-treated fistulated animals. At the completion of the VFI determination the animals were fed at 1.035 of VFI for $4 \mathrm{~d}$, after which the rumen was completely emptied (bailing) to determine rumen pool size. Before bailing the animals were sedated with $20 \mathrm{mg}$ xylazine (Rompun; Bayer AG) but remained standing. The rumen digesta was removed from the fistula, weighed, subsampled for triplicate DM determinations, and then kept 
warm over a bucket of warm water $\left(70^{\circ}\right)$. To determine rumen capacity (i.e. volume) a deflated, softer rubber meteorological balloon (Totex Corporation, Japan) was then placed inside the empty rumen and filled with water $\left(24^{\circ}\right)$, from a tared water-tank, through rubber tubing (i.d. $5 \mathrm{~mm}$ ) placed in the neck of the balloon. The balloon was estimated to be full when the balloon and water had accommodated all parts of the rumen. The waterfilled rumen capacity was calculated as the loss in weight of the water container. The water from the balloon was then siphoned out of the rumen and warmed rumen digesta returned to the animal. The whole process lasted about 45 min per animal.

\section{Heart rate}

Heart rate was measured using one control and one MEL-treated animal daily. Pregelled adhesive silver chloride electrodes with press-studs $(39 \mathrm{~mm}$ diameter; Medicotest, Denmark) were glued to the closely-clipped skin of the animals on the dorso-lumbar and axillary regions (one per location). A portable electrocardiograph (ECG; Cardisuny $501 \mathrm{~A}$; Fukuda M-E (Medical Electronics); Kogyo Co. (Ltd), Japan) was used to detect and record cardiopotentials from the body of the animals. Recording was on high-sensitivity chart paper (Z-fold type; Fukuda M-E (Medical Electronics), Kogyo Co. (Ltd), Japan) with a chart drive of $25 \mathrm{~mm} / \mathrm{s}$ and the calibration signal being $1 \mathrm{mV}$ square wave. Recording was done with the animals standing, under resting conditions, at intervals over a period of $45 \mathrm{~min}$.

\section{Radioimmunoassay procedures}

Plasma MEL concentrations were determined by direct radioimmunoassay (RIA) as described by Fraser et al. (1983) using duplicate samples of plasma $(0.5 \mathrm{ml})$. The antiserum (704/8483; Guildhary Antisera, University of Surrey, Guildford, UK) was raised in a sheep against $\mathrm{N}$-acetyl-5-methoxytryptophan-bovine thyroglobulin and used at a final dilution of 1:8000. Low-, medium- and high-melatonin standard reference samples were included at frequent intervals in each assay. The inter-assay coefficients of variation ( $\%$ ) were 27.5 for the low $(n 30 ;$ mean $21.4 \mathrm{pg} / \mathrm{ml}), 17.2$ for the medium $(n 30 ;$ mean $121 \mathrm{pg} / \mathrm{ml})$ and 15.8 for the high reference samples $(n 29$; mean $510 \mathrm{pg} / \mathrm{ml})$. The intra-assay coefficients of variation $(\%)$ were $21 \cdot 0,10 \cdot 7$ and $10 \cdot 1$ respectively for the three reference samples. Sensitivity was $10 \mathrm{pg} / \mathrm{ml}$.

PRL was determined using a modification of the method of Van Landeghem \& van der Weil (1978) as validated for red deer plasma (S. N. McCutcheon, unpublished results). The first antibody was raised in rabbits against ovine PRL and was supplied by National Institute of Arthritis, Diabetes \& Health, Bethesda, Maryland, USA (Code and lot no. NIAD DK-Anti-oPRL-1, AFP-973269). It was stored frozen at 1:100 dilution in assay buffer and was further diluted to 1:40000 for the assay. Rabbit $\gamma$-globulin was added to the first antibody mix to provide $1 \mu \mathrm{g}$ per assay tube to facilitate formation of the antibody pellet. The second antibody was a donkey anti-rabbit precipitating serum IDS Gamma-B precipitating antiserum for radioimmunoassay (Code APPT1, lot no. 11656; IDS, Washington, Tyne and Wear, UK). The sensitivity of the assay was an average of $0.3 \mu \mathrm{g} / \mathrm{l}$, the inter-assay coefficient of variation was $14.0 \%$ and the intra-assay coefficient of variation was $9 \cdot 1 \%$.

\section{Chemical analysis}

The DM of the rumen digesta samples was determined by freeze-drying for $5 \mathrm{~d}$ until no further loss in weight was recorded (FD 57 freeze-dryer; WGG Cuddon (NZ) Ltd). Total nitrogen content of feed samples was determined by the Kjeldahl method, whilst in vitro digestibility was determined by the method of Roughan \& Holland (1977). 


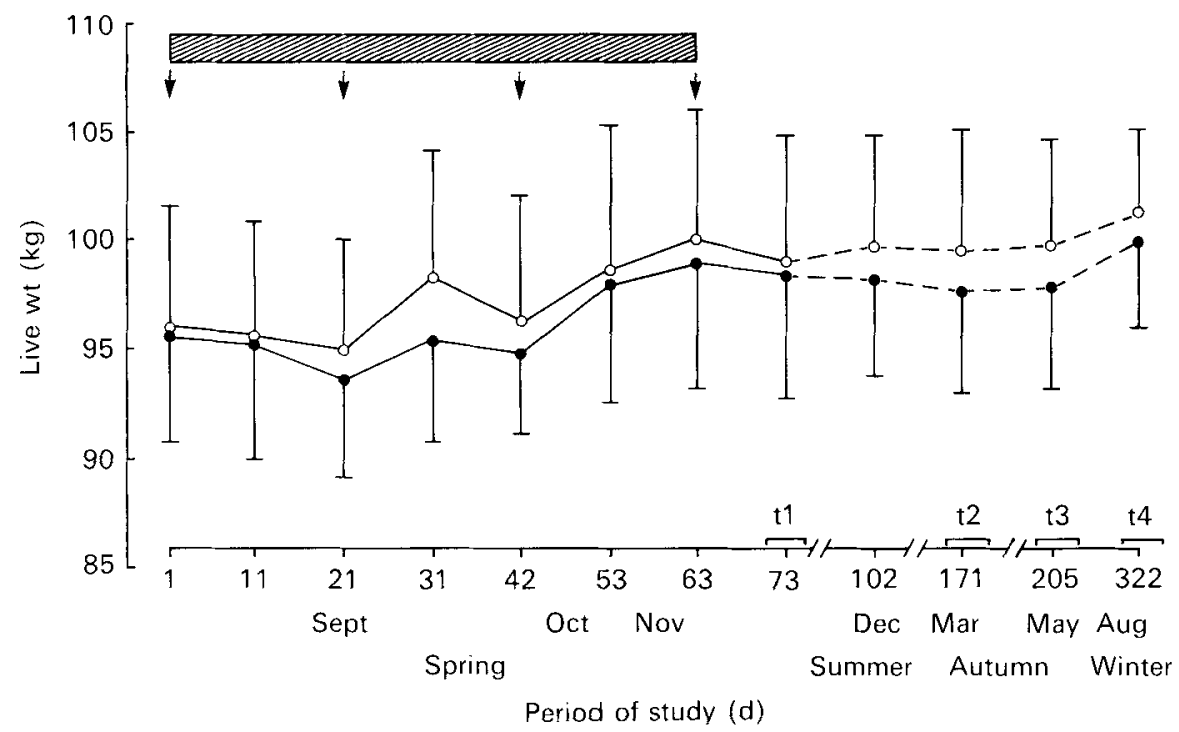

Fig. 1. Changes in live weight over a 12-month period in castrated male red deer (Cervus elaphus) kept under natural daylength. (O), Control deer; $(O)$, melatonin-implanted deer; $(\triangle)$, period of melatonin implantation (spring); subcutaneous melatonin implant. Points are means with 1 sEM represented by vertical bars. For details of procedures, see pp. 7879.

\section{Statistical analysis}

Effects of time and of time $\times$ MEL interactions were assessed by repeat-measures analysis of variance (Cole \& Grizzle, 1966) using the SAS statistical program. Where the interactions were significant, repeat-measures contrast-variables analysis was used to define the timeperiods in which the responses to MEL were different. Between-subjects effects were calculated and found to be non-significant $(P>0.05)$ in all analyses. A one-way analysis of variance was also conducted at each sampling time, from which the standard errors on Figs. 1-7 were calculated.

\section{RESULTS}

\section{Effects of MEL treatment on live weight}

Fig. 1 shows that treatment with sc MEL implants did not affect live weight either during or following the period of implantation. The castrated male deer showed very little evidence of seasonal patterns in live weight with only a very small increase in weight during spring and summer and no evidence of significant weight loss during autumn.

\section{Effects of sc MEL implants on day-time plasma concentrations of MEL and PRL}

By $11 \mathrm{~d}$ after the first sc MEL implants the mean day-time MEL concentration rose from 4 to $154 \mathrm{pg} / \mathrm{ml}$ (Fig. 2(a)). Mean day-time MEL concentrations declined to $116 \mathrm{pg} / \mathrm{ml} 21 \mathrm{~d}$ from implantation and steadily decreased thereafter to a mean of $60 \mathrm{pg} / \mathrm{ml}$ by day 42 of MEL treatment. This was followed by an increase in the day-time plasma MEL concentration which averaged $140 \mathrm{pg} / \mathrm{ml}$ between days 53 and 73 . The control group showed almost undetectable day-time plasma MEL concentrations during the sampling period. By day 205 (5 April 1989) the mean day-time plasma MEL concentration in the MEL-treated group had declined to $31 \mathrm{pg} / \mathrm{ml}$, whilst in the control group it was $4 \mathrm{pg} / \mathrm{ml}$.

Mean plasma PRL concentration (Fig. 2(b)) in control animals was high during spring and declined during autumn (April) and winter (August). During the period of MEL 

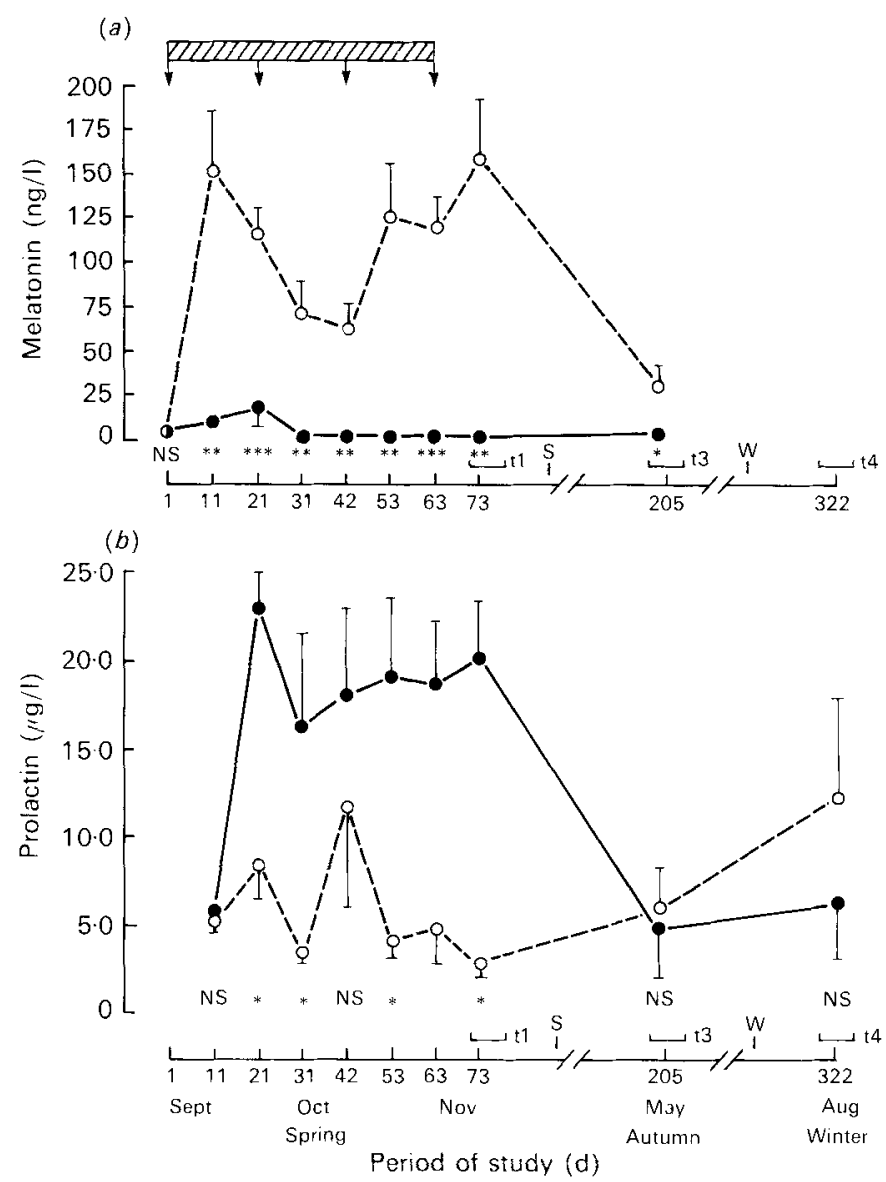

Fig. 2. Plasma concentrations of $(a)$ melatonin and $(b)$ prolactin over a 12-month period in castrated male red deer (Cervus elaphus) kept under natural daylength. (O), Control deer; $(\mathrm{O})$, melatonin-implanted deer; ( $(\lambda)$, period of melatonin implantation (spring); $\mathrm{t} t, \mathrm{t} 3, \mathrm{t} 4$, periods of indoor feeding; $\downarrow$, subcutaneous melatonin implant; $S$, summer solstice; W, winter solstice. Points are means with 1 SEM represented by vertical bars. NS, not significant. Mean values were significantly different from those of control deer: ${ }^{*} P<0 \cdot 05,{ }^{* *} P<0 \cdot 01$, *** $P<0 \cdot 001$. For details of procedures, sce p. 80.

administration, mean plasma PRL concentration was lower in implanted than in control animals $(P<0 \cdot 05)$. Thereafter, plasma PRL concentrations rose in implanted animals during autumn and winter.

Effects of MEL treatment on VFI, rumen pool size, rumen capacity and heart rate

Control animals showed high values for VFI, rumen pool size and heart rate in late spring and summer and low values in autumn and winter (Figs. 3-7). The time $\times$ MEL interaction was significant at $P<0.01$ for VFI and at $P<0.05$ for rumen pool size, and approached significance for heart rate $(P=0 \cdot 11)$. The analysis of contrast variables showed that the response to MEL during summer (t2) was not different to that during spring ( 11 ) for all three criteria; however, the response to MEL was different from that during spring for VFI during autumn (t3; $P<0.01)$ and winter (t4; $P<0.001)$, for rumen pool size during autumn $(P<0.01)$ and winter $(P<0.05)$ and for heart rate during autumn $(P<0.05)$ and winter $(P<0.05)$. The response to MEL between seasons was different at higher levels of 


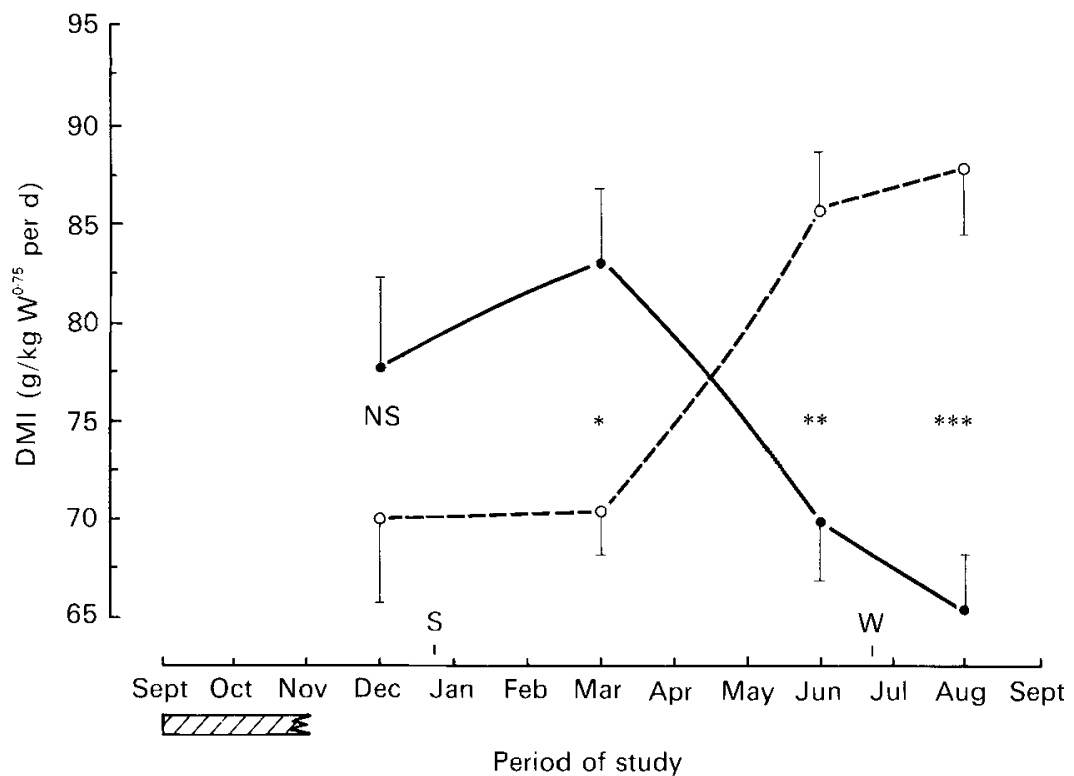

Fig. 3. Voluntary dry matter intake (DMI; g/kg live weight $(W)^{0.75}$ per d) over a 12 -month period in castrated male red deer (Cervus elaphus) kept under natural daylength. (O), Control deer; ( $\bigcirc)$, melatonin-implanted deer; $(\oslash)$, period of melatonin implantation (spring); S, summer solstice; W, winter solstice. Points are means with 1 SEM represented by vertical bars. NS, not significant. Mean values were significantly different from those of control deer: ${ }^{*} P<0 \cdot 05,{ }^{* *} P<0.01 ;{ }^{* * *} P<0.001$. For details of procedures, see pp. 79-80.

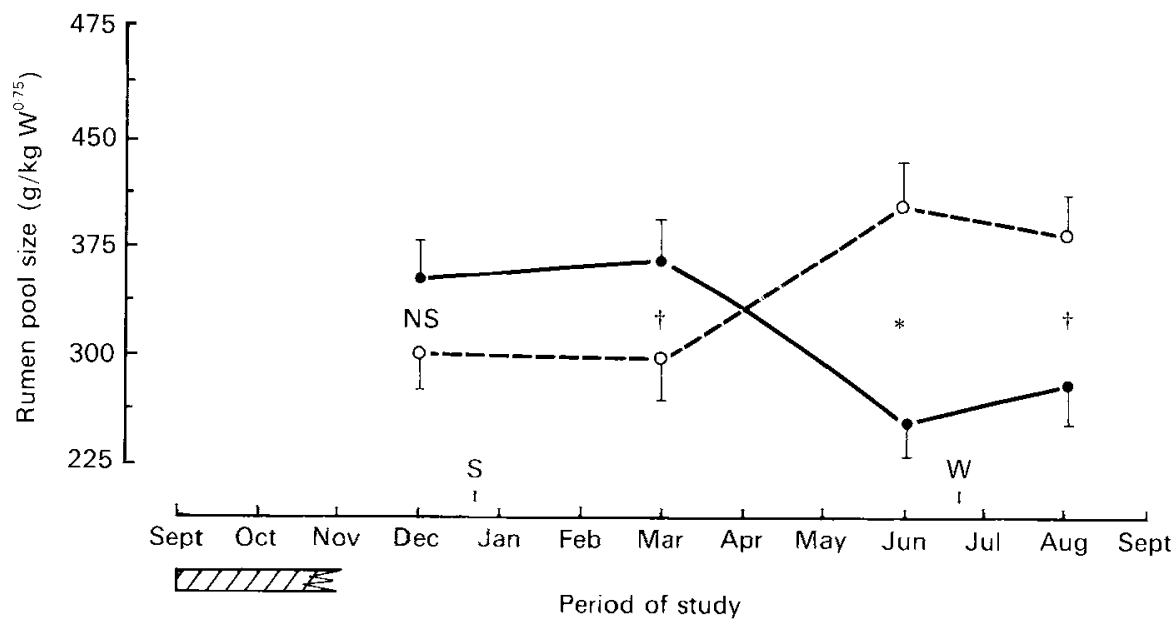

Fig. 4. Rumen pool size (dry matter (DM) + liquid; $g / k g$ live weight $(W)^{6 \cdot 75}$ ) over a 12 -month period in castrated male red deer (Cervus elaphus) kept under natural daylength. (O), Control deer; (O), melatonin-implanted deer; (Q), period of melatonin implantation (spring); S, summer solstice; W, winter solstice. Points are means with I SEM represented by vertical bars. NS, not significant. Mean values were significantly different from those of control deer: ${ }^{*} P<0 \cdot 05,+P<0 \cdot 10$. For details of procedures, see pp. $79-80$.

significance when comparisons were made between summer and winter for VFI $(P<$ $0.001)$, rumen pool size $(P<0.01)$ and heart rate $(P<0.01)$. These analyses are consistent with MEL implants depressing all three criteria during spring and summer and increasing all three above those of control animals during autumn and winter. 

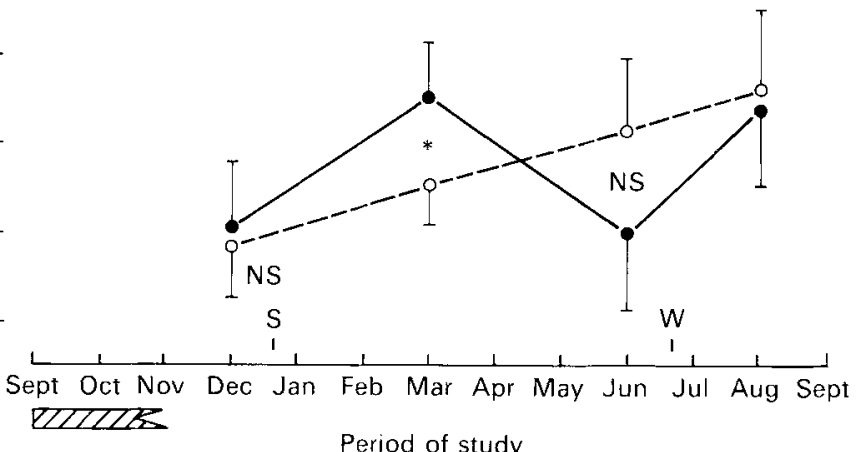

Fig. 5. Rumen capacity over a 12-month period in castrated male red deer (Cervus elaphus) kept under natural daylength. (O), Control deer; (O) melatonin-implanted deer; ( $\circlearrowright$ ), period of melatonin implantation (spring); $\mathrm{S}$, summer solstice; W, winter solstice. Points are means with 1 sEM represented by vertical bars. NS, not significant. Mean values were significantly different from those of control deer: ${ }^{*} P<0.05$. For details of procedures, see p. 80 .

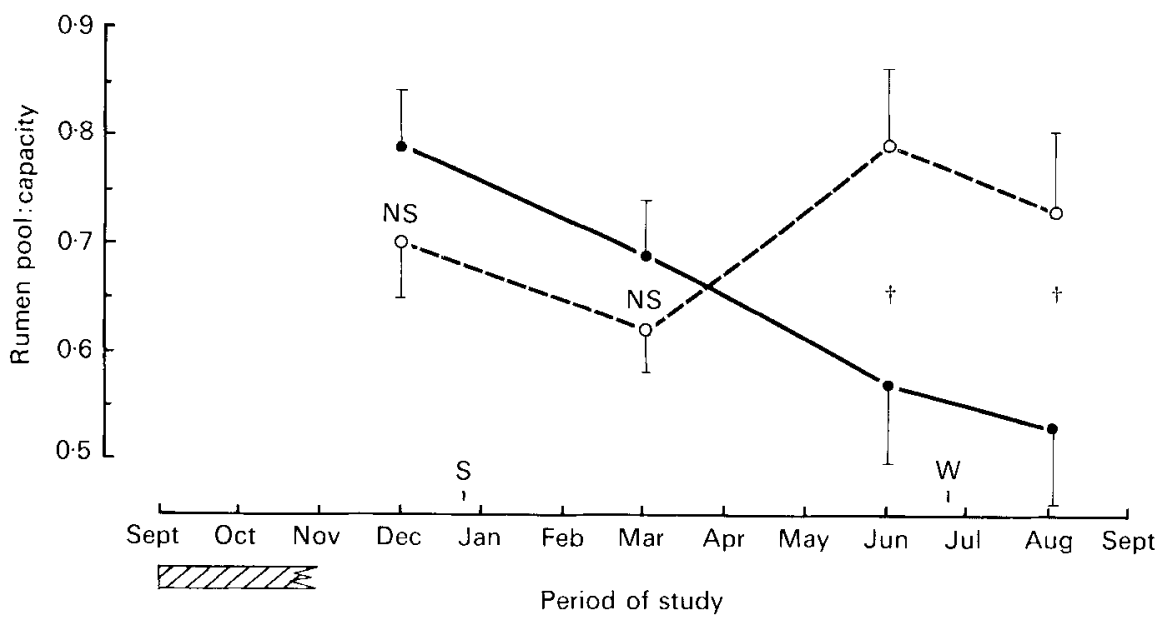

Fig. 6. Proportion of total rumen capacity occupied by rumen contents over a 12 -month period in castrated male red deer (Cervus elaphus) kept under natural daylength. (O), Control deer; $(\bigcirc)$, melatonin-implanted deer; ( $\oslash)$, period of melatonin implantation (spring); S, summer solstice; W, winter solstice. Points are means with 1 SEM represented by vertical bars. NS, not significant. Mean values were significantly different from those of control deer: $\uparrow P<0 \cdot 10$. For details of procedures, see p. 80 .

Rumen capacity (Fig. 5) showed no significant effects of time and there was no MEL $\times$ time interaction, showing that this was relatively constant. Rumen pool/rumen capacity showed no significant time $\times$ MEL interaction; however, in control animals it progressively declined with time $(P<0.05)$ and there was some evidence in MEL-treated deer that it rose with VFI during winter (Fig. 6).

\section{Coat colour}

Control deer grew their normal thin brown coat over summer and longer, thicker dark brown winter coats. MEL-treated deer shed their summer coats and grew thick, long winter-type coats in late summer and possessed normal summer coats during winter. This 


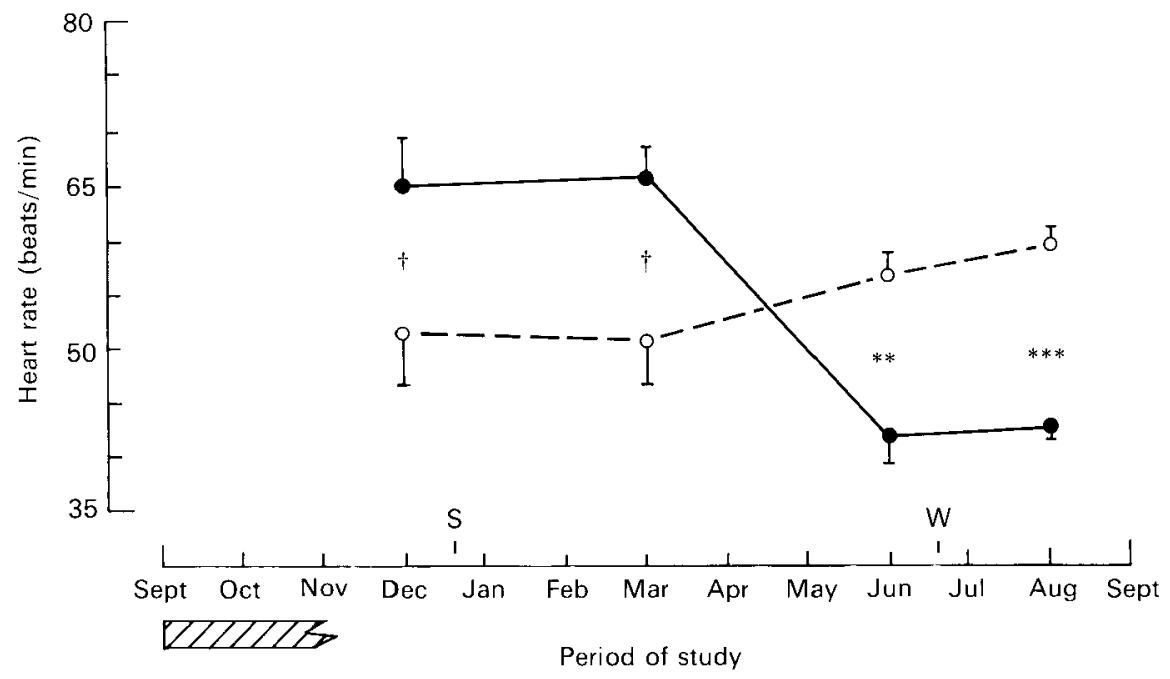

Fig. 7. Seasonal changes in heart rate over a 12-month period in castrated male red deer (Cervus elaphus) kept under natural daylength. (O), Control deer; (O), melatonin-implanted deer; $(\triangle)$, period of melatonin implantation (spring); S, summer solstice; $W$, winter solstice. Points are means with 1 SEM represented by vertical bars. NS, not significant. Mean values were significantly different from those of control deer: $* * P<0 \cdot 01,{ }^{* * *} P$ $<0 \cdot 001,+P<0 \cdot 10$. For details of procedures, see p. 80 .

reversed cycle of coat type persisted in MEL-treated deer for a further 12 months after the experimental period concluded, but thereafter these deer returned to their normal cycle of coat development.

\section{DISCUSSION}

Exogenous constant-release MEL implants increased day-time plasma MEL concentration significantly in the present study, and this was kept at high levels during the treatment period of $63 \mathrm{~d}$. The progressive decline in day-time plasma levels observed between days 21 and 42 suggests that exogenous MEL may have been metabolized rapidly by the deer over this time-period, or that the efficacy of the second implant was low, but the progressive increase over days 42 and 63 suggests that this was a transitory phase. At day 205, $140 \mathrm{~d}$ after the last MEL implants, the day-time MEL plasma concentration of MEL-treated animals showed a marked decline but had not reached the normal day-time concentration of control deer, indicating that the implants were not yet completely exhausted. Asher et al. (1988) reported that plasma MEL concentrations in fallow deer (Dama dama; $50 \mathrm{~kg}$ live weight) declined to normal day-time levels $60 \mathrm{~d}$ after the last implant, following a MEL implantation regimen of three $18 \mathrm{mg}$ doses at $30 \mathrm{~d}$ intervals. It seems that a longer period was required in the present study (95 kg live weight) to exhaust the MEL implants completely, due to the higher dose rate used (four $36 \mathrm{mg}$ implants at $21 \mathrm{~d}$ intervals).

The results of the present experiment showed seasonal cycles in VFI, rumen pool size and heart rate in control deer, with maximum values in summer and minimum values in winter. MEL administration for $63 \mathrm{~d}$ during spring appeared to change this seasonal rhythm by approximately 6 months, with minimum values for these criteria occurring in summer and maximum values in winter. It thus seems that a period of high plasma MEL concentration in late spring-early summer suppressed the summer high values in the seasonal cycle, replacing these with low values. The results of the present study suggest that red deer possess endogenous cycles in VFI, rumen pool size and heart rate, and that a period of high plasma MEL concentration commencing in spring moved the timing of the cycles by about 
6 months without otherwise affecting them. In a review (Barry et al. 1991) it was proposed that MEL secretion is the mechanism whereby reproductive rhythms in deer are synchronized to photoperiod, with MEL being predominantly secreted during hours of darkness; it was also suggested that rhythms of VFI may be entrained to photoperiod by the same mechanism. The results of the present study suggest that this could well be the system which synchronizes seasonal changes in digestive function and body metabolism to photoperiod.

In a comparative study Loudon et al. (1989) showed that seasonal changes in VFI, coat length and colour, reproduction and plasma concentration of a number of hormones all occurred approximately $60 \mathrm{~d}$ earlier in Père David deer (Elaphunus davidianus) than in red deer. As all criteria were similarly affected, this illustrates that they are 'phase-locked' in deer and, hence, may have a common cause. Milne et al. (1990) reached a similar conclusion from oral MEL administration to non-lactating red deer hinds during summer-autumn which advanced the cycles of reproduction and VFI by 23 and $14 \mathrm{~d}$. Similar 'phase-locked' effects are apparent in the present study, with subcutaneous MEL administration in spring advancing the cycles of VFI, rumen pool size, heart rate and coat type, but the magnitude of advancement in these cycles was much greater than that observed by Milne et al. (1990).

The precise mechanism of how MEL affects the timing of these cycles is unknown. PRL administration during winter has been shown to increase VFI and live-weight gain in reindeer (Ryg \& Jacobsen, 1982) and in weaned red deer (J. M. Suttie, personal communication) but to have no effect in domestic sheep (Eisemann et al. 1984). Thus, PRL may be a hormone involved in the regulation of seasonal cycles in animals that show this mechanism physiologically, such as red deer, but not in species that have lost this trait, such as the domestic sheep. The positive relationship between plasma PRL concentration and VFI in the present study, for both MEL-treated and control deer, suggests that one way by which MEL may influence seasonal cycles is through affecting PRL secretion. Further experimentation in this area is required.

Although the control castrated male deer in the present study showed pronounced seasonal trends in VFI, rumen pool size, heart rate and coat colour, they showed hardly any evidence of seasonal changes in live weight. This is in marked contrast to entire red deer stags of the same age which have a larger amplitude to their VFI cycle than do castrates, and show a large reduction in live weight during the period of sexual activity in autumn (i.e. the rut) and a corresponding increase in live weight during spring and summer (Kay, 1985). The entire red deer stag has peaks of luteinizing hormone production over summer and testosterone production over the autumn rut (Lincoln \& Kay, 1979); it seems that these are important in regulation of the annual weight-change cycle. Heart rate is strongly related to energy expenditure (heat production) in deer (Moen, 1978, 1985) as in other species. Thus, the lack of effect of MEL administration on live weight changes can probably be explained by the effects of MEL on energy expenditure counteracting those of VFI.

Rumen capacity has been proposed to limit VFI of ruminants consuming forage diets (Black, 1990), and it has been suggested that red deer may be able to increase rumen capacity during summer thus accommodating their seasonal increase in VFI (Milne et al. 1978; Milne, 1980). However, results of the present study showed that rumen capacity remained relatively constant, and that one mechanism used by red deer to increase VFI was to increase rumen pool size as a proportion of total capacity. The linear nature of this relationship for control deer suggests that, under the conditions of the present study, rumen capacity was not a constraint to increasing VFI during summer.

Since MEL is the hormone synchronizing the seasonal cycle of VFI (and associated rumen cycles) to photoperiod, it is important to understand the hormonal basis of these cycles and their implications for the applied nutrition of farmed deer. As a consequence of 
their seasonal cycles, farmed young entire red deer stags grow rapidly in late spring-summer but poorly in winter, even when given the same food in all seasons (Fennessy et al. 1981; Ataja et al. 1990). Slow growth during winter is a major constraint to efficient venison production in New Zealand. One possibility for increasing winter growth rates, and hence VFI, concerns active immunization against MEL (Duckworth \& Barrell, 1989; Ataja et al. 1990). If commenced at birth this may cause the young deer to show less marked seasonal rhythms, improved winter growth and, hence, a greater response to nutrition over this critical period.

Technical assistance by Ms C. M. C. Jenkinson, statistical advice by Dr I. L. Gordon and statistical analyses by Dr D. O. Freudenberger are gratefully acknowledged.

\section{REFERENCES}

Arendt, J. (1979). Radioimmunoassayable melatonin : circulating patterns in man and sheep. Progress in Brain Research 52, 249-258.

Asher, G. W., Barrell, G. K., Adam, J. L. \& Staples, L. D. (1988). Effects of subcutaneous melatonin implants on reproductive seasonality of farmed fallow deer (Dama dama). Journal of Reproduction and Fertility 84, 679-691.

Ataja, A. M., Wilson, P. R., Purchas, R. W., Hodgson, J., Varela-Alvarez, H. \& Barry, T. N. (1990). Responses in venison production to immunisation against melatonin and to grazing pastures based upon perennial or annual ryegrass. Proceedings of the New Zealand Society of Animal Production 50, 279-285.

Barry, T. N., Suttie, J. M., Milne, J. A. \& Kay, R. N. B. (1991). Control of food intake in domesticated deer. In Physiological Aspects of Digestion and Metabolism in Ruminants. Proceedings of the VIIth International Symposium on Ruminant Physiology, Sendai, Japan, pp. 385-401 [T. Tsuda, Y. Sasaki and R. Kawashima editors] San Diego: Academic Press.

Bittman, E. L., Dempsey, R. J.\& Karsch, F. J. (1983). Pineal melatonin secretion drives the reproductive response to day-length in the ewe. Endocrinology 113, 2276-2283.

Black, J. L. (1990). Nutrition of the grazing ruminant. Proceedings of the New Zealand Society of Animal Production 50, 727.

Bubenik, G. A. (1983). Shift of seasonal cycle in white-tailed deer by oral administration of melatonin. Journal of Experimental Zoology 225, 155-156.

Cole, J. W. L. \& Grizzle, J. E. (1966). Applications of multivariate analysis of variance to repeated measurements experiments. Biometrics 22, 810-828.

Curlewis, J. D., Loudon, A. S. I. \& Coleman, A. P. M. (1988). Oestrous cycles and the breeding season of the Père David's deer hind (Elaphunus davidianus). Journal of Reproduction and Fertility 82, 119-126.

Domingue, B. M. F. (1989). A comparative study of voluntary intake and rumen digestion by deer, goats and sheep. PhD Thesis, Massey University, Palmerston North, New Zealand.

Duckworth, J. A. \& Barrell, G. K. (1989). Effect of melatonin immunisation on live-weight gain of red deer. Proceedings of the New Zealand Society of Animal Production 49, 29-34.

Eisemann, J., Bauman, D. E., Hogue, D. E. \& Travis, H. F. (1984). Evaluation of a role for prolactin in growth and the photoperiod-induced growth response in sheep. Journal of Animal Science 59, 86-94.

Fennessy, P. F., Moore, G. H. \& Corson, I. D. (1981). Energy requirements of red deer. Proceedings of the New Zealand Society of Animal Production 41, 167-173.

Fisher, M. W., Fennessy, P. F. \& Milne, J. D. (1988). Effects of melatonin on seasonal physiology of red deer. Proceedings of the New Zealand Society of Animal Production 48, 113-116.

Forbes, J. M., Driver, P. M., Brown, W. B., Scanes, G. G. \& Hart, I. C. (1979). The effect of daylength on the growth of lambs. 2. Blood concentrations of growth hormone, prolactin, insulin and thyroxine, and the effect of feeding. Animal Production 29, 43 . 51.

Fraser, S., Cowen, P. \& Franklin, M. (1983). Direct radioimmunoassay for melatonin in plasma. Clinical Chemistry 29, 396-397.

Kay, R. N. B. (1985). Body size, patterns of growth, and the efficiency of production in red deer. $\ln$ Biology of Deer Production. Royal Society of New Zealand Bulletin no. 22, pp. $411-422$ [P. F. Fennessy and K. R. Drew, cditors]. Wellington, New Zealand: Royal Society of New Zealand.

Kennaway, D. J., Dunstan, E. A., Gilmore, T. A. \& Seamark, R. E. (1983). Effects of short daylength and melatonin treatment on plasma prolactin and melatonin levels in pinealectomized and sham-operated ewes. Animal Reproduction Science 5, 287-294.

Lincoln, G. A. \& Ebling, F. J. P. ( 1985). Effect of constant-release implants of melatonin on seasonal cycles in reproduction, prolactin secretion and moulting in rams. Journal of Reproduction and Fertility 73, $241-253$.

Lincoln, G. A. \& Kay, R. N. B. (1979). Effects of season on the secretion of LH and testosterone in intact and castrated red deer stags. Journal of Reproduction and Fertility 55, 75-80. 
Loudon, A. S. I., Milne, J. A., Curlewis, J. D. \& McNeilly, A. S. (1989). A comparison of seasonal hormone changes and patterns of growth, voluntary food intake and reproduction in juvenile and adult red deer (Cervus elaphus) and Père David's deer (Elaphumus davidianus) hinds. Journal of Endocrinology 122, 733-745.

Milne, J. A. (1980). Comparative digestive physiology and metabolism of the red deer and sheep. Proceedings of the New Zealand Society of Animal Production 40, 151-157.

Milne, J. A., McRae, J. C., Spence, A. M. \& Wilson, S. (1978). A comparison of the voluntary intake and digestion of a range of forages at different times of the year by the sheep and the red decr (Cervus elaphus). British Journal of Nutrition 40,346-357.

Milne, J. A., Loudon, A. S. I., Sibbald, A. M, Curlewis, J. D. \& McNeilly, A. S. (1990). Effects of melatonin and a dopamine agonist and antagonist on seasonal changes in voluntary intake, reproductive activity and plasma concentrations of prolactin and tri-iodothyronine in red deer hinds. Journal of Endocrinology, 125, 241-249.

Moen, A. N. (1978). Seasonal changes in heart rates, activity, metabolism, and forage intake of white-tailed deer. Journal of Wildlife Management 42, 715 738.

Moen, A. N. (1985). Energy metabolism of deer in relation to environmental variables. In Biology of Deer Production. Royal Society of New Zealand Bulletin no. 22, pp. 439445 [P. F. Fennessy and K. R. Drew, editors]. Wellington, New Zealand: Royal Society of New Zealand

Plotka, E. D., Seal, U. S., Letellier, M. A., Verme, L. J. \& Ozaga, J. J. (1981). Effect of pinealectomy on seasona] phenotypic changes in white-tailed deer (Odocoileus virginianus borealis). In Pineal Function, pp. 45-56 [C. D. Matthews and R. F. Seamark, editors]. Amsterdam: Elsevier/North Holland.

Poulton, A. L., English, J., Symons, A. M. \& Arendt, J. (1986). Effects of various melatonin treatments on plasma prolactin concentrations in the ewe. Journal of Endocrinology 108, 287292.

Poulton, A. L., English, J., Symons, A. M. \& Arendt, J. (1987). Changes in plasma concentrations of LH, FSH and prolactin in ewes receiving melatonin and short photoperiod to induce early onset of breeding activity. Journal of Endocrinology 112, 103-111.

Roughan, P. G. \& Holland, R. (1977). Predicting in vivo digestibilities of herbage by exhaustive enzymic hydrolysis of cell walls. Journal of the Science of Food and Agriculture 28, 10571064.

Ryg, M. \& Jacobsen, E. (1982). Effects of thyroid hormones and prolactin on food intake and weight changes in young male reindeer (Rangifer tarandus tarandus). Canadian Journal of Zoology 60, 1562-1567.

Silver, H., Colovos, N. F., Holter, J. B. \& Hayes, H. H. (1969). Fasting metabolism of white-tailed deer. Journal of Wildlife Management 33, 490-498.

Simpson, A. M., Suttie, J. M. \& Kay, R. N. B. (1984). The infuence of artificial photoperiod on the growth, appetite and reproductive status of male red deer and sheep. Animal Reproduction Science 6, 291-299.

Suttic, J. M., Corson, I. D. \& Fennessy, P. F. (1984). Voluntary intake, testis development and antler growth patterns of male Red Deer under a manipulated photoperiod. Proceedings of the New Zealand Society of Animal Production 44, 167-170.

Suttie, J. M. \& Kay, R. N. B. (1985). Influence of plane of winter nutrition on plasma concentrations of prolactin and testosterone and their association with voluntary food intake in red deer stags (Cervus elaphus). Animal Reproduction Science 8, 247-258.

Suttie, J. M. \& Simpson, A. M. (1985). Photoperiodic control of appetite, growth, antlers, and endocrine status of red deer. In Biology of Deer Production. Royal Society of New Zealand Bulletin no. 22, pp. $429-432$ [P. F. Fennessy and K. R. Drew, editors]. Wellington, New Zealand: Royal Society of New Zealand.

Van Landeghem, A. A. J. \& van der Weil, D. F. M. (1978). Radioimmunoassay for porcine prolactin; plasma levels during suckling, lactation and weaning, and after TRH administration. Acta Endocrinologica 88, 653.667.

Webster, J. R. \& Barrell, G. K. (1985). Advancement of reproductive activity, seasonal reduction in prolactin secretion and seasonal pelage changes in pubertal red deer hinds (Cervus elaphus) subjected to artificially shortened daily photoperiod of daily melatonin treatments. Journal of Reproduction and Fertility 73, $255-260$.

Wilson, P. R. (1991). Field studies of advancing the breeding season in farmed red deer using melatonin implants: two dosage regimes and the influence of the stag. In Biology of Deer, pp 313-319 [R. D. Brown, editor]. New York: Springer-Verlag.

Wilson, P. R., Walker, I. H., Middleberg, A., Bond, D. B. \& Staples, L. D. (1991). Field evaluation of melatonin implants to advance the breeding season in one-year-old red deer hinds. New Zealand Veterinary Journal 39 : $23-28$

Wurtman, R. J. \& Anton-Tay, F. (1969). The mammalian pineal as a neuroendocrine transducer. Recent Progress in Hormone Research 25, 493-522. 